\title{
Ozone oxidation of antidepressants in wastewater -Treatment evaluation and characterization of new by-products by LC-QToFMS
}

André Lajeunesse ${ }^{1}$, Mireille Blais ${ }^{2}$, Benoît Barbeau ${ }^{2}$, Sébastien Sauvé ${ }^{3}$ and Christian Gagnon ${ }^{*^{*}}$

\begin{abstract}
Background: The fate of 14 antidepressants along with their respective $\mathrm{N}$-desmethyl metabolites and the anticonvulsive drug carbamazepine was examined in a primary sewage treatment plant (STP) and following advanced treatments with ozone $\left(\mathrm{O}_{3}\right)$. The concentrations of each pharmaceutical compound were determined in raw sewage, effluent and sewage sludge samples by LC-MS/MS analysis. The occurrence of antidepressant by-products formed in treated effluent after ozonation was also investigated.

Results: Current primary treatments using physical and chemical processes removed little of the compounds (mean removal efficiency: 19\%). Experimental sorption coefficients ( $\left.K_{d}\right)$ of each studied compounds were also calculated. Sorption of venlafaxine, desmethylvenlafaxine, and carbamazepine on sludge was assumed to be negligible (log $\left.K_{d} \leq 2\right)$, but higher sorption behavior can be expected for sertraline (log $\mathrm{K}_{d} \geq 4$ ). Ozonation treatment with $\mathrm{O}_{3}(5 \mathrm{mg} / \mathrm{L})$ led to a satisfactory mean removal efficiency of $88 \%$ of the compounds. Screening of the final ozone-treated effluent samples by high resolution-mass spectrometry (LC-QqToFMS) did confirm the presence of related N-oxide by-products.
\end{abstract}

Conclusion: Effluent ozonation led to higher mean removal efficiencies than current primary treatment, and therefore represented a promising strategy for the elimination of antidepressants in urban wastewaters. However, the use of $\mathrm{O}_{3}$ produced by-products with unknown toxicity.

Keywords: Antidepressants, Ozone, LC-MS/MS, Sewage treatment plants, Biosolids, Side-products

\section{Background}

Urban wastewaters are one of the major sources of pharmaceutically-active compounds (PhACs) into aquatic environments [1,2]. The elimination of many pharmaceuticals in sewage treatment plants (STPs) being often incomplete [3-5], effluents from STPs thus contribute to a significant load of pharmaceutical residues in the receiving waters [6]. Little is however known on the potential release of transformation by-products following advanced wastewater treatments.

Among the most prescribed PhACs throughout the world are the psychiatric drugs that include the

\footnotetext{
* Correspondence: christian.gagnon@ec.gc.ca

'Environment Canada, Wastewater and Effluents Section, Water Science and Technology Directorate, 105 McGill Street, Montreal, Quebec H2Y 2E7, Canada

Full list of author information is available at the end of the article
}

antidepressants and the antiepileptic drug carbamazepine (CAR) frequently used for treating schizophrenia and bipolar disorder [7,8]. The persistent drug CAR largely sold in Canada is currently prescribed in combination to antidepressants all over the world during therapy. Therefore, a monitoring of CAR is also required to better assess its environmental fate in different matrices. Toxicity studies of these neuroactive compounds provided evidence for biological effects on aquatic organisms [9-13]. Although the occurrence of antidepressants in sewage effluents [6,14-17] and wastewater sludge [18-20] has been demonstrated, the fate of these substances following different treatments in STPs has not been extensively documented. A previous study indicated that a primary treatment process has limited capability to remove and/or degrade antidepressants residues in wastewater [15]. Further results
(C) Chemistry Central

C 2013 Lajeunesse et al.; licensee Chemistry Central Ltd. This is an Open Access article distributed under the terms of the Creative Commons Attribution License (http://creativecommons.org/licenses/by/2.0), which permits unrestricted use, distribution, and reproduction in any medium, provided the original work is properly cited. 
obtained for STPs operating different biological processes (e.g. secondary treatment with activated sludge) revealed moderate potential (mean removal efficiency $\leq 30 \%$ ) to degrade antidepressants from wastewater [20]. Therefore, alternative treatment technologies may have to be implemented or combined to achieve high removal of compounds in STPs [21]. As such, experimental evidence reported elsewhere clearly demonstrates that existing limitations in primary and secondary processes can be overcome with more advanced treatment strategies including chemical oxidation with ozone or the use of high pressure membrane technologies [22-24].

While conventional activated sludge treatments were shown to degrade pharmaceuticals to varying extent [25], ozone $\left(\mathrm{O}_{3}\right)$ treatments showed promising results in terms of removal efficiencies as an efficient oxidizer to remove endocrine disruptors compounds and pharmaceuticals products in wastewater [26,27]. Generally, $\mathrm{O}_{3}$ reacts with organic molecules through either the direct reaction with molecular $\mathrm{O}_{3}$ (via 1-3 dipolar cyclo addition reaction on unsaturated bonds, and electrophilic reaction on aromatics having electron donor groups e.g. $\mathrm{OH}, \mathrm{NH}_{2}$ ) or by decomposition through the formation of chain intermediate free radicals, including the hydroxyl radical $\mathrm{OH}$ • (less selective reaction on saturated aliphatic molecules) [26,28]. The stability of dissolved ozone is readily affected by $\mathrm{pH}$, ultraviolet (UV) light, ozone concentration, and the concentration of radical scavengers such carbonate - bicarbonate species, the dissolved organic carbon and humic acids $[28,29]$. Except for few experiments completed with fluoxetine (FLU), the number of studies dedicated to the elimination of antidepressants by oxidation processes (e.g. $\mathrm{TiO}_{2}$ membrane reactor, $\mathrm{O}_{3}$ with $\mathrm{UV}$ activation, $\mathrm{O}_{3}$ with $\mathrm{H}_{2} \mathrm{O}_{2}$ ) has been rather limited [22-24]. Since molecular $\mathrm{O}_{3}$ is a selective electrophile that reacts quickly with amine and double bounds moieties [26], ozonation should be efficient to degrade antidepressants mostly constituted of secondary or tertiary amine and conjugated rings. However, as reported for $\beta$-Lactam antibacterial agents (e.g. penicillin $G$, cephalexin) spiked in wastewater, $\mathrm{O}_{3}$ reaction leads to the formation of biologically active sulfoxides analogues [30]. For antidepressants, no study on the transformation products following an $\mathrm{O}_{3}$ treatment in wastewater is currently available. As yet, no data is reported neither on by-products toxicity. Nevertheless, formation of $\mathrm{N}$-oxide, amide, aldehyde, and carboxylic acid by-products is expected after ozonation of secondary and tertiary amine compounds in aqueous solutions $[31,32]$.

In the present work, the effectiveness of ozone treatments in terms of removal efficiency is tested at three different concentrations for the oxidation of 14 antidepressants along with their direct $\mathrm{N}$-desmethyl metabolites and the anticonvulsive drug carbamazepine during ozonation of a primary-treated effluent. The goal of the study was also to investigate the occurrence of antidepressant by-products formed in treated effluent after ozonation.

\section{Experimental}

\section{Chemicals and materials}

All certified standards were $>98 \%$ purity grade. Fluoxetine (FLU), norfluoxetine (NFLU), paroxetine (PAR), sertraline (SER), (S)-citalopram (CIT), fluvoxamine (FLUVO), desmethylfluvoxamine (DFLUVO), mirtazapine (MIR), and desmethylmirtazepine (DMIR) were provided by Toronto Research Chemicals Inc. (North York, Ontario, Canada). Desmethylsertraline (DSER), venlafaxine (VEN), O-desmethylvenlafaxine (DVEN), and the surrogate standard bupropion- $d_{9}$ were obtained from Nanjing Jinglong PharmaTech (Nanjing, China). Amitriptyline (AMI), nortriptyline (NTRI), carbamazepine (CAR), and surrogate standard 10,11-dihydrocarbamazepine were purchased from Sigma-Aldrich Co. (St. Louis, Missouri, USA), while internal standard cis-tramadol ${ }^{13} \mathrm{C}-d_{3}$ was purchased from Cerilliant Corp. (Round Rock, Texas, USA). The high-performance liquid chromatography-grade solvents (methanol and acetonitrile) and ammonium hydroxide were provided by Caledon Laboratories Ltd. (Georgetown, Ontario, Canada). Reagent-grade hydrochloric acid, acetic acid, ammonium bicarbonate, and ACS grade ethyl acetate were provided by American Chemicals Ltd. (Montreal, Quebec, Canada). Solid-phase extraction (SPE) cartridges of $6 \mathrm{~mL}, 200 \mathrm{mg}$ Strata $^{\mathrm{TM}}$ X-C were purchased from Phenomenex (Torrance, California, USA). Stock solutions of $100 \mathrm{mg} / \mathrm{L}$ of each substance were prepared in methanol and stored at $4{ }^{\circ} \mathrm{C}$ in amber glass bottles that were previously washed with methanol. The chemical structures of the selected compounds are provided in Figure 1.

\section{Instrumentation}

\section{Liquid chromatography (LC)}

Liquid chromatography (LC) was performed using an Agilent 1200 Series LC system equipped with binary pumps, degasser, and a thermostated autosampler maintained at $4{ }^{\circ} \mathrm{C}$. The antidepressants were separated on a Kinetex ${ }^{\circledR}$ XB-C18 column $(100 \mathrm{~mm} \times 2.10 \mathrm{~mm}, 1.7 \mu \mathrm{m})$ using a binary gradient made of (A) ammonium bicarbonate $(5 \mathrm{mM}) \mathrm{pH} 7.8$, and $(\mathrm{B})$ acetonitrile at a flow rate of $400 \mu \mathrm{L} / \mathrm{min}$. The volume of injection was $15 \mu \mathrm{L}$ for influent, effluent, and sludge extracts. The gradient used was (\%B): 0 min (10\%), 6 min (80\%), $10 \mathrm{~min}(80 \%), 12 \mathrm{~min}$ (90\%), 14 min (10\%), and 16 min (10\%). An equilibration time of 4 min was used resulting in a total run time of $20 \mathrm{~min}$. The column temperature was maintained at $40^{\circ} \mathrm{C}$.

\section{Tandem-mass spectrometry (QqQMS, QqToFMS)}

For quantitative analysis, the LC system was coupled to a 6410 triple quadrupole mass spectrometer (QqQMS) manufactured by Agilent Technologies (Santa Clara, CA, 


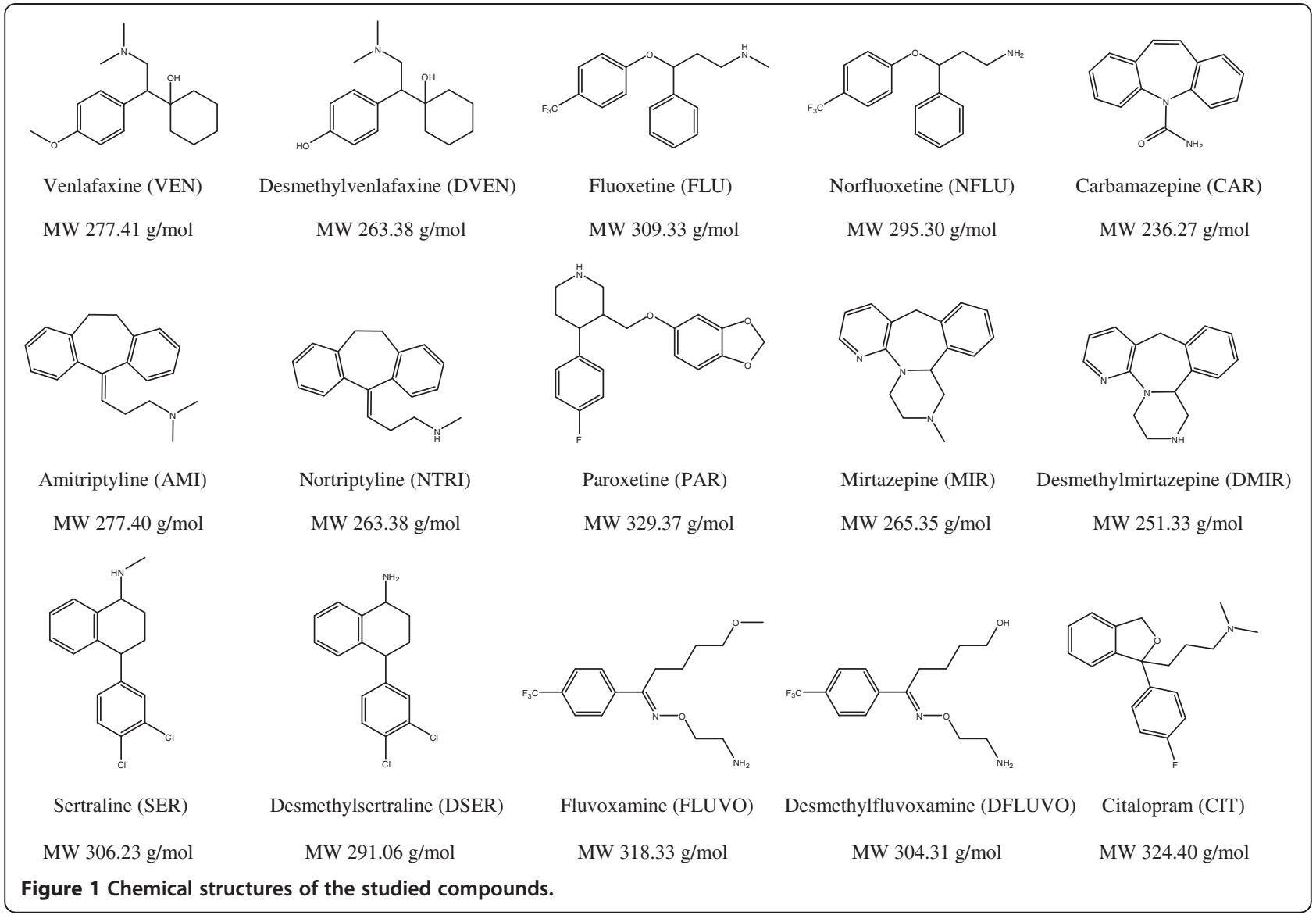

USA) equipped with an electrospray ionization (ESI) source. The capillary was maintained at $4000 \mathrm{~V}$, and the cone voltage was optimized for each compound in the positive-ion mode (ESI+). Additional detector parameters were held constant for all antidepressants: gas temperature $325^{\circ} \mathrm{C}$; gas flow $10 \mathrm{~L} / \mathrm{min}$; nebulizer 35 psi and dwell time $50 \mathrm{~ms}$. For qualitative by-products analysis, a 6530 quadrupole time-of-flight mass spectrometer (QqToFMS) also manufactured by Agilent Technologies, was utilized. The QqToFMS was equipped with a thermal gradient focusing ESI source (Jet Stream technology). Source parameters consisted of the following: gas temperature $325^{\circ} \mathrm{C}$; sheath gas temperature $350^{\circ} \mathrm{C}$; sheath gas flow $11 \mathrm{~L} / \mathrm{min}$; drying gas flow $5 \mathrm{~L} / \mathrm{min}$; nebulizer $35 \mathrm{psig}$, fragmentor $100 \mathrm{~V}$ and capillary voltage $4000 \mathrm{~V}$. The QqToFMS was operated in the $4 \mathrm{GHz}$ High Resolution mode with a low mass range $(1700 \mathrm{~m} / z)$. Purine $(121.050873 \mathrm{~m} / \mathrm{z})$ and Hexakis $(922.009798 \mathrm{~m} / \mathrm{z})$ were used as internal reference masses to improve mass accuracy. Initial tests were performed on treated effluent extracts in high resolution tandem MS mode using a mass range of $\mathrm{m} / \mathrm{z}$ 100-400 (specific collision energy: $0 \mathrm{~V}$ ) at a rate of 5 spectra/s to screen the exact $[\mathrm{M}+\mathrm{H}]^{+}$masses of the precursor ions. Identified compounds were then fragmented with different specific collision energies varying between 0 and $10 \mathrm{~V}$. For both detection systems, the MassHunter software from Agilent Technologies was used for data acquisition and processing. Optimized parameters for QqQMS are listed in a table (Additional file 1).

\section{Sample location and collection Sample location}

All samples were collected onsite at the sewage treatment plant (STP) of the city of Repentigny (30 km North-East of Montreal, Qc, Canada) in amber glass bottles previously washed with methanol during an ozonation pilot-study performed in June 2011. The Repentigny STP typically treats $25000 \mathrm{~m}^{3}$ of raw sewage daily for a population of approximately 60000 persons. Wastewater is primarytreated using both physical and chemical treatments (e.g. flocculation of suspended matters with alum and/or $\mathrm{FeCl}_{3}$ ). For the purpose of this study, treated wastewater was further experimentally ozone-oxidized on site. Main characteristics of the Repentigny STP are reported in Table 1. Ozonation of the effluent consisted of an ozone $\left(\mathrm{O}_{3}\right)$ generator (Ozone Solution, Model: TG10-Ozone Solution) fed with ultra-pure oxygen (99.9999\%). Gaseous ozone was bubbled in a ceramic diffuser located inside a 
Table 1 Main water characteristics of the Repentigny sewage treatment plant

\begin{tabular}{lcccccc}
\hline Wastewater & Temperature $\left({ }^{\circ} \mathbf{C}\right)$ & $\mathbf{p H}$ & Alkalinity $(\mathbf{m g} / \mathbf{L}) \mathbf{C a C O}_{\mathbf{3}}$ & TSS (mg/L) & $\mathbf{B O D}_{\mathbf{5}}(\mathbf{m g} / \mathbf{L})$ & $\mathbf{C O D}(\mathbf{m g} / \mathbf{L})$ \\
\hline Raw sewage (Influent) & 17 & 7.3 & 189 & 146 & 136 & 227 \\
Effluent & - & 7.2 & 165 & 12 & 36 & 59 \\
\hline
\end{tabular}

TSS: Total Suspended Solids, BOD: Biochemical Oxygen Demand, COD: Chemical Oxygen Demand.

vertical column (6.3 m, 5.08 internal diameter) where both gas transfer and contact time occurred simultaneously. The water flow was maintained at $1.2 \mathrm{~L} / \mathrm{min}$, while the $\mathrm{O}_{3}$ flow rate injection was kept around 75 to $110 \mathrm{~N} \mathrm{~mL} / \mathrm{min}$ (head pressure: $10 \mathrm{psi}$ ). Contact time of $\mathrm{O}_{3}$ with treated effluent was $10 \mathrm{~min}$. Ozone transfer was monitored by measuring off-gas ozone concentrations using the standard KI procedure [33]. Applied ozone dosages were then corrected for ozone transfer efficiency which varied from 75 to $80 \%$. Total and residual dissolved $\mathrm{O}_{3}$ concentrations were determined following the standard indigo trisulfonate colorimetric method [34].

\section{Sample collection}

Typically, water samples of influent (raw sewage), primarytreated effluent, and ozone treated effluent were collected between 10:00 and 14:00 in polyethylene containers and stored on ice. Samples of wet primary sewage sludge (biosolids) were also collected on the same days and immediately stored on ice in polyethylene bottles. In the laboratory, approximately $10 \mathrm{~g}$ of wet biosolid material was filtered with a $0.7 \mu \mathrm{m}$ glass fiber filter to get a dewatered sludge sample that was frozen, freeze-dried, and stored at $-80^{\circ} \mathrm{C}$ until use. All samples were extracted and analyzed within $48 \mathrm{~h}$ after their collection.

\section{Sample extraction}

\section{Sewage samples}

Extraction method for raw sewage and effluent samples to be analyzed for various classes of antidepressants was done as previously described [15]. The decision to incorporate the neutral drug carbamazepine (CAR) amongst the basic antidepressants forced us to modify the protocol by replacing the strong cation exchange cartridge by a mixedmode cartridge for sample purification (Strata X-C, Phenomenex) [20].

The validated extraction protocol used here was similar to that described in Lajeunesse et al. [20]. Each $250 \mathrm{~mL}$ of filtered sewage sample were spiked with $100 \mu \mathrm{L}$ of a surrogate standard solution prepared in methanol (bupropion- $d_{9} /$ 10,11-dihydrocarbamazepine, $2.5 \mathrm{mg} / \mathrm{L}$ ) and addition of $2.5 \mathrm{~mL}$ of methanol before lowering the $\mathrm{pH}$ to around 3 with $100 \mu \mathrm{L}$ of phosphoric acid (85\%). The mixed-mode solid phase extraction (SPE) cartridges were conditioned with $4 \mathrm{~mL}$ of methanol followed by at least $8 \mathrm{~mL}$ of Milli-Q water. SPE was performed with a VAC ELUT SPS24 manifold (Varian) at flow rates $\sim 10-15 \mathrm{~mL} / \mathrm{min}$. After extraction, all cartridges were washed with $2 \mathrm{~mL}$ of $\mathrm{HCl}(0.1 \mathrm{M})$. The CAR molecules were eluted first with $2 \times 2 \mathrm{~mL}$ of ethyl acetate prior the evaporation of the solvent in the tubes to dryness under a gentle stream of nitrogen.

Table 2 Mean concentrations of studied compounds extracted in wastewater (raw sewage, effluent) and biosolid samples from the Repentigny STP

\begin{tabular}{|c|c|c|c|c|c|c|}
\hline \multirow[t]{2}{*}{ Compounds } & \multicolumn{3}{|c|}{ Wastewaters $(n=2)$} & \multicolumn{3}{|c|}{ Biosolids $(n=2)$} \\
\hline & Raw sewage (ng/L) & Effluent (ng/L) & Removal Eff. (\%) & Sludge (ng/g) & $\mathrm{K}_{\mathrm{d}}(\mathrm{L} / \mathrm{kg})$ & $\log K_{d}$ \\
\hline $\mathrm{CIT}$ & $207 \pm 12$ & $148 \pm 16$ & 29 & $172 \pm 38$ & $1.2 \times 10^{3}$ & 3.1 \\
\hline SER & $13 \pm 1$ & $9.4 \pm 0.1$ & 28 & $43 \pm 5$ & $4.6 \times 10^{3}$ & 3.7 \\
\hline DSER & $23 \pm 1$ & $19 \pm 3$ & 17 & $31 \pm 6$ & $1.6 \times 10^{3}$ & 3.2 \\
\hline AMI & $223 \pm 21$ & $195 \pm 11$ & 13 & $58 \pm 22$ & $2.9 \times 10^{2}$ & 2.5 \\
\hline NTRI & $21 \pm 3$ & $19 \pm 4$ & 6.8 & $9.0 \pm 1.1$ & $4.7 \times 10^{2}$ & 2.7 \\
\hline VEN & $4061 \pm 153$ & $3144 \pm 107$ & 23 & $227 \pm 49$ & $7.2 \times 10^{1}$ & 1.9 \\
\hline DVEN & $4185 \pm 133$ & $3448 \pm 279$ & 18 & $73 \pm 2$ & $2.1 \times 10^{1}$ & 1.3 \\
\hline CAR & $747 \pm 14$ & $714 \pm 13$ & 4.4 & $26 \pm 12$ & $3.6 \times 10^{1}$ & 1.6 \\
\hline FLU & $11 \pm 1$ & $9.5 \pm 0.6$ & 16 & $15 \pm 1$ & $1.6 \times 10^{3}$ & 3.2 \\
\hline NFLU & $7.0 \pm 0.4$ & $6.5 \pm 0.2$ & 7.1 & $3.8 \pm 0.6$ & $5.8 \times 10^{2}$ & 2.8 \\
\hline PAR & $15 \pm 1$ & $13 \pm 4$ & 9.0 & $5.6 \pm 3.6$ & $4.2 \times 10^{2}$ & 2.6 \\
\hline MIR & $171 \pm 20$ & $109 \pm 3$ & 36 & $27 \pm 6$ & $2.5 \times 10^{2}$ & 2.4 \\
\hline DMIR & $41 \pm 1$ & $25 \pm 1$ & 38 & $13 \pm 1$ & $5.4 \times 10^{2}$ & 2.7 \\
\hline
\end{tabular}




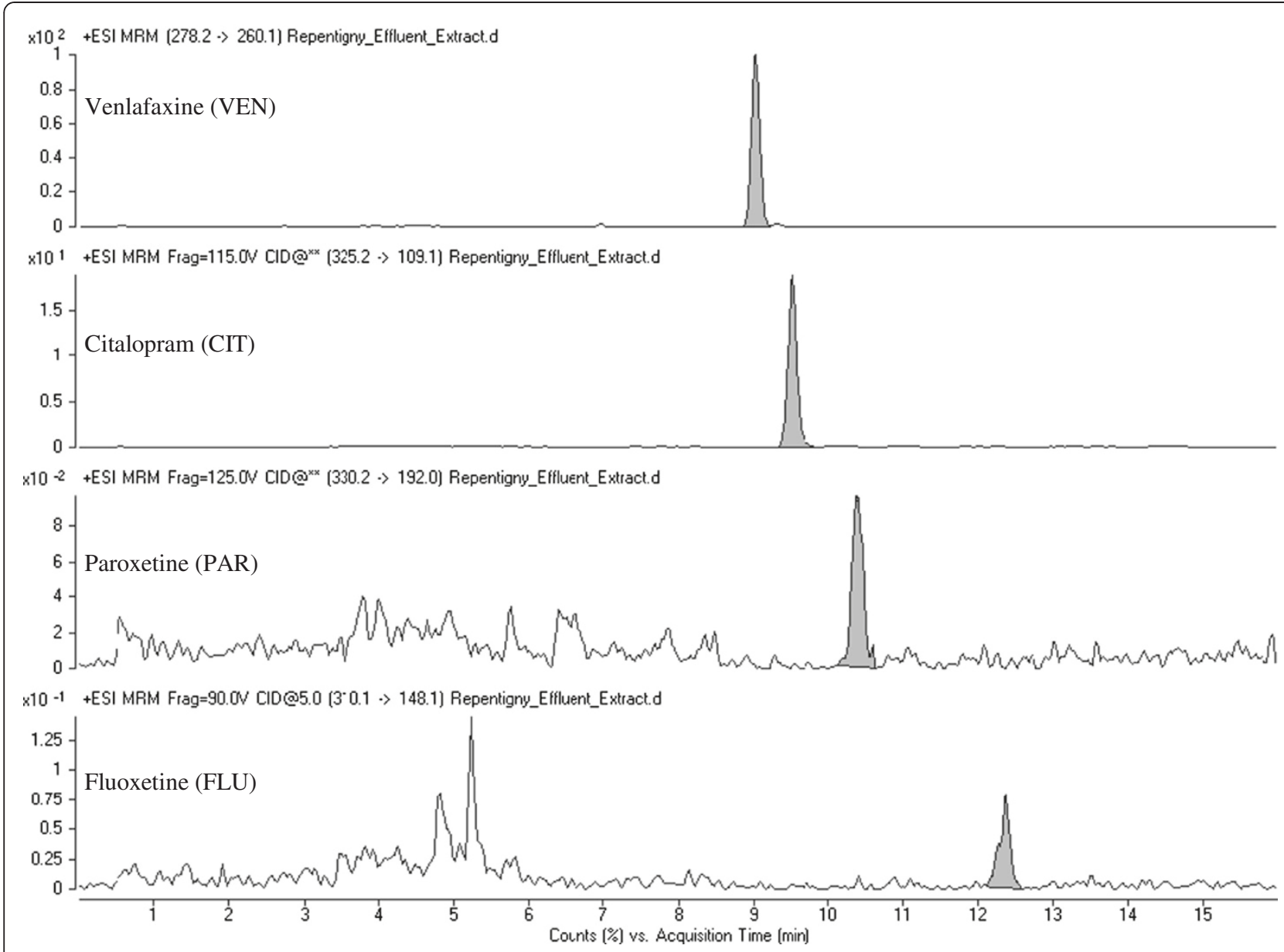

Figure 2 Representative LC-QqQMS chromatograms of selected antidepressants detected in primary-treated effluent sample extract.

Meanwhile, all SPE cartridges were washed with $2 \mathrm{~mL}$ of methanol. The antidepressants retained onto the sorbent were then eluted with $2 \times 2 \mathrm{~mL}$ of a solution of $5 \%(\mathrm{v} / \mathrm{v})$ $\mathrm{NH}_{4} \mathrm{OH}$ in methanol. The combined fractions (e.g. CAR and antidepressants) were mixed with $100 \mu \mathrm{L}$ of a solution of cis-tramadol ${ }^{13}-d_{3}$ in methanol $(5 \mathrm{mg} / \mathrm{L})$ as the internal standard and the solvent in tubes was evaporated to dryness with nitrogen. The dried extracts were reconstituted with $0.50 \mathrm{~mL}$ of the mobile phase solution of ammonium bicarbonate (5 mM) pH 7.8 - acetonitrile $(1: 1 \mathrm{v} / \mathrm{v})$ in injection vials and later injected in LC-QqQMS or LC-QqToFMS for analysis.

\section{Sewage sludge samples}

The simultaneous extraction of CAR and antidepressants in biosolid samples was completed using the validated protocol reported in Lajeunesse et al. [20]. Briefly, $0.200 \mathrm{~g}$ of freeze-dried sludge is transferred to a $16 \times 150 \mathrm{~mm}$

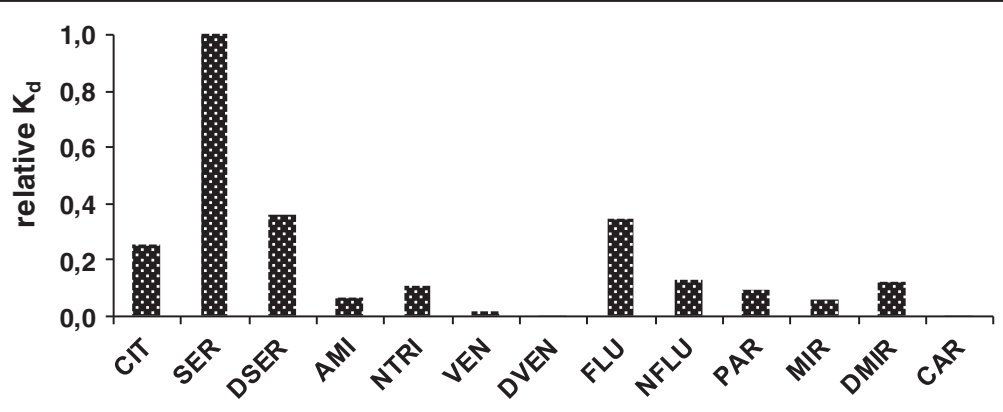

Figure 3 Relative $K_{d}$ values of the studied compounds. 
Table 3 Mean concentrations and removal of antidepressants contained in final effluent following ozonation

\begin{tabular}{|c|c|c|c|c|c|c|}
\hline \multirow[t]{2}{*}{ Compounds } & \multicolumn{3}{|c|}{ Conc. $(\mathrm{n}=2)$ Ozone $5 \mathrm{mg} / \mathrm{L}$} & \multicolumn{3}{|c|}{ Conc. $(n=2)$ Ozone $9 \mathrm{mg} / \mathrm{L}$} \\
\hline & Effluent (ng/L) & Disinfected effluent (ng/L) & Removal Eff. (\%) & Effluent (ng/L) & Disinfected effluent (ng/L) & Removal Eff. (\%) \\
\hline $\mathrm{CIT}$ & $186 \pm 27$ & $123 \pm 11$ & 34 & $148 \pm 16$ & $56 \pm 1$ & 62 \\
\hline SER & $14 \pm 2$ & - & 100 & $9.4 \pm 0.1$ & - & 100 \\
\hline DSER & $23 \pm 1$ & - & 100 & $19 \pm 3$ & - & 100 \\
\hline AMl & $106 \pm 5$ & $36 \pm 1$ & 66 & $195 \pm 11$ & $15 \pm 1$ & 92 \\
\hline NTRI & $18 \pm 1$ & $0.18 \pm 0.01$ & 99 & $19 \pm 4$ & - & 100 \\
\hline VEN & $2194 \pm 191$ & $963 \pm 43$ & 56 & $3144 \pm 107$ & $986 \pm 27$ & 69 \\
\hline DVEN & $2319 \pm 11$ & - & 100 & $3448 \pm 279$ & - & 100 \\
\hline CAR & $716 \pm 4$ & $12 \pm 1$ & 98 & $714 \pm 13$ & - & 100 \\
\hline FLU & $6.3 \pm 0.8$ & - & 100 & $9.5 \pm 0.6$ & - & 100 \\
\hline NFLU & $11 \pm 2$ & - & 100 & $6.5 \pm 0.2$ & - & 100 \\
\hline PAR & $9.0 \pm 1.3$ & - & 100 & $13 \pm 4$ & - & 100 \\
\hline MIR & $104 \pm 1$ & $1.6 \pm 0.1$ & 98 & $109 \pm 3$ & - & 100 \\
\hline DMIR & $41 \pm 4.1$ & $3.3 \pm 0.4$ & 92 & $25 \pm 1$ & - & 100 \\
\hline
\end{tabular}

Note: Measured residual $\mathrm{O}_{3}$ concentrations for 5,9 and $13 \mathrm{mg} / \mathrm{L}$ of $\mathrm{O}_{3}$ were respectively $0.000,0.036$ and $0.514 \mathrm{mg} / \mathrm{L}$.

borosilicate glass screw-top conical tube before adding $8 \mathrm{~mL}$ of a solution composed of methanol / $0.1 \mathrm{M}$ acetic acid buffer solution $\mathrm{pH} 4.0(1: 1 \mathrm{v} / \mathrm{v})$. Each tube were spiked with $100 \mu \mathrm{L}$ of a surrogate standard solution prepared in methanol (bupropion- $d_{9} /$ 10,11-dihydrocarbamazepine, $2.5 \mathrm{mg} / \mathrm{L}$ ). Samples were then shaken vigorously and mixed on a rotary extractor (Caframo REAX) for $15 \mathrm{~min}$. After extraction, tubes were placed in a sonication bath for $15 \mathrm{~min}$ before adding $4 \mathrm{~mL}$ of Milli-Q water to each tube. Tubes were then centrifuged (320 x g) at room temperature for $5 \mathrm{~min}$. Following the SPE protocol described previously for aqueous sewage samples, supernatants were transferred directly on mixed-mode cartridges. The final extracts were reconstituted in $0.5 \mathrm{~mL}$ of the mobile phase solution of ammonium bicarbonate $(5 \mathrm{mM}) \mathrm{pH} 7.8$ - acetonitrile $(1: 1 \mathrm{v} / \mathrm{v})$, filtered with a
PTFE $0.45 \mu \mathrm{m}$ filter, and then injected in LC-QqQMS system for analysis.

\section{Results and discussion}

Antidepressants in raw sewage and primary-treated effluent

Out of the 15 compounds investigated, 13 were detected in raw sewage samples and only the antidepressant FLUVO and its direct metabolite DFLUVO were not detected. Compound concentrations ranged from $6.5 \mathrm{ng} / \mathrm{L}$ (NFLU) to $4185 \mathrm{ng} / \mathrm{L}$ (DVEN) (Table 2). A typical chromatogram of the detected antidepressants VEN, CIT, PAR, and FLU in a primary-treated effluent extract is depicted in Figure 2. Overall, moderate to poor removal efficiencies were obtained for most antidepressants (mean removal efficiency of $19 \%)$. Results showed that current enhanced primary

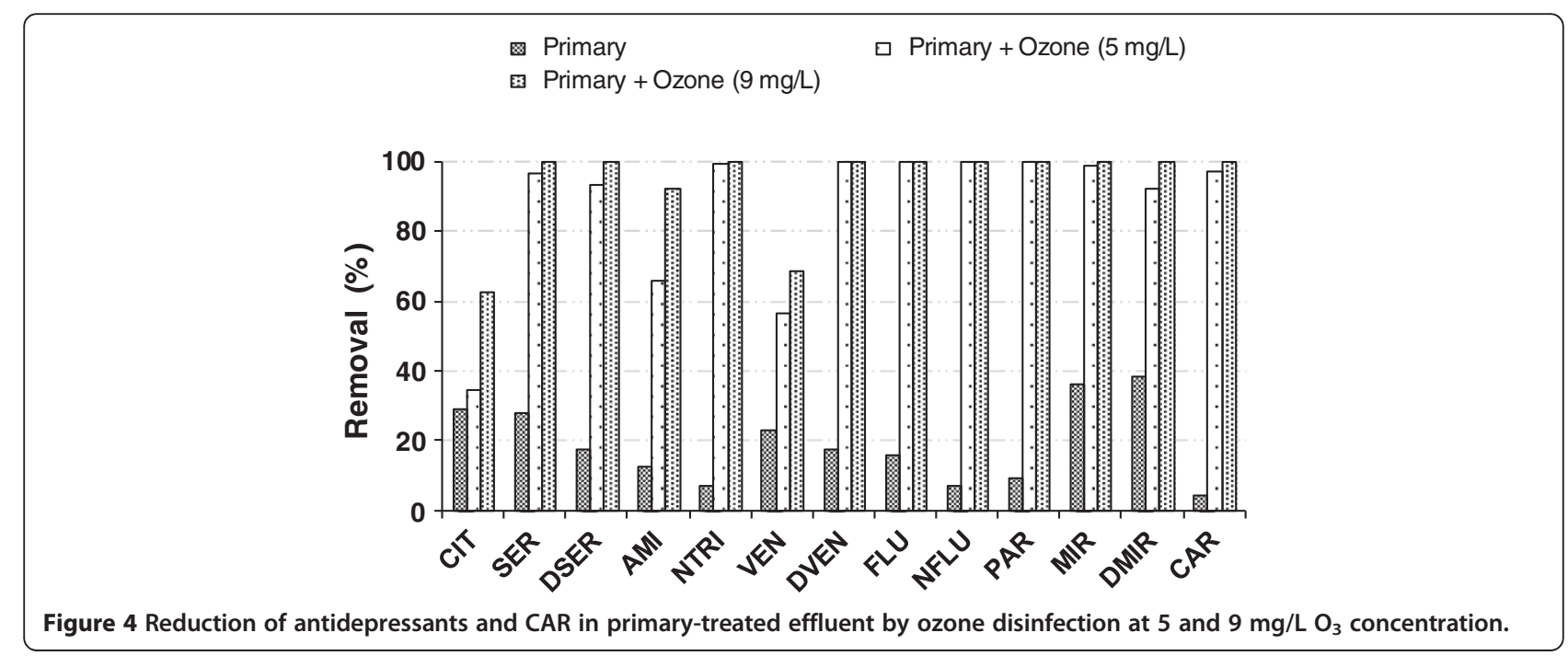




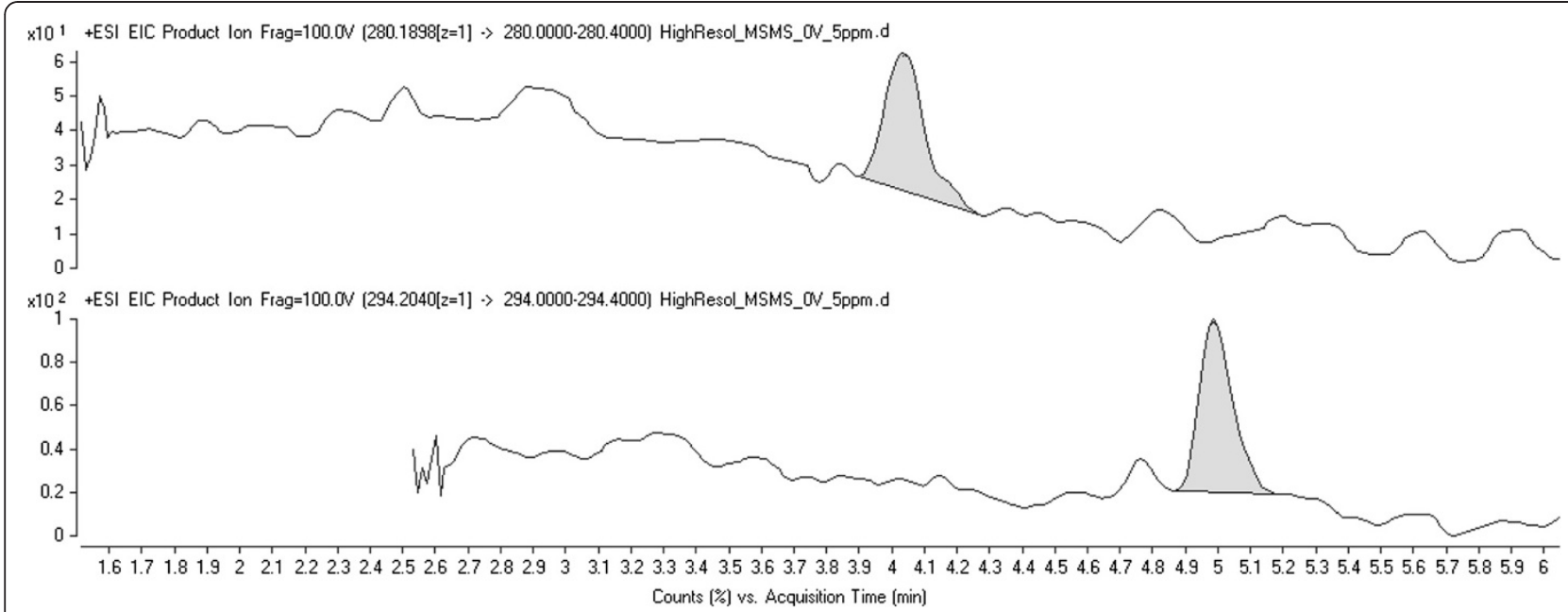

Figure 5 LC-QqToFMS chromatograms of $\mathrm{N}$-oxide by-products detected in disinfected effluent $\left(\mathrm{O}_{3}\right.$ concentration: $\left.5 \mathrm{mg} / \mathrm{L}\right)$.

treatment using physical and chemical processes removed little of the studied compounds (Table 2). The substances with lowest removal efficiencies were CAR (4.4\%), along with the antidepressant metabolites NTRI (6.8\%) and NFLU (7.1\%). Similar low removal rates were previously reported for antidepressants [15] and CAR [35] in primarytreated effluents. Despite a noteworthy reduction of total suspended solids - TSS (Table 1), the weak removal obtained for this primary treatment strongly suggests that a mechanism other than chemical adsorption would be required to effectively remove antidepressants from urban wastewater.

\section{Antidepressants in sewage sludge}

Primary sludge samples consistently displayed quantifiable amounts of the studied compounds (excepted FLUVO and
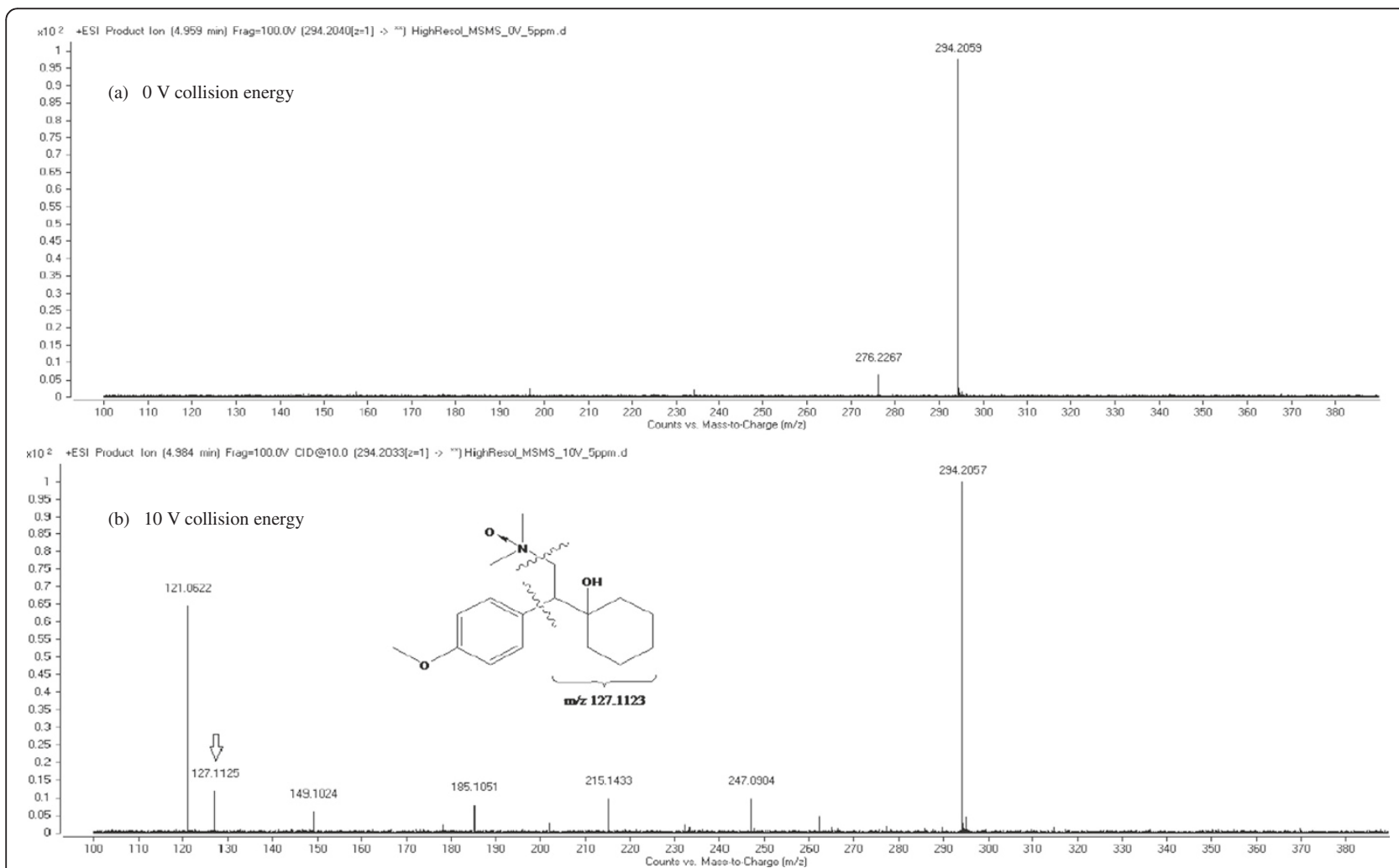

Figure 6 LC-QqToFMS mass spectra of $\mathrm{N}$-oxide VEN in disinfected effluent $\left(\mathrm{O}_{3}\right.$ concentration: $\left.5 \mathrm{mg} / \mathrm{L}\right)$ : product ions at $0 \mathrm{~V}$ collision energy (a) and $10 \mathrm{~V}$ collision energy (b). 
DFLUVO) (Table 2). Highest mean concentrations in biosolid samples were found for VEN (227 ng/g), CIT (172 ng/g), DVEN (70 ng/g), AMI (58 ng/g), and SER (43 ng/g). Our results are consistent with the mean concentrations for the antidepressants FLU (123 ng/g) and PAR (41 ng/g) reported by Radjenović et al. [18] in primary sludge samples. Interestingly, among reported concentrations, less antidepressant metabolites were detected in sewage sludge samples for $N$-desmethyl metabolites in comparison to their respective parent molecules. These findings suggest that more polar compounds have a lower affinity for the solid phase of sewage sludge and hence have limited removal efficiencies.

In order to describe the fate and behavior of antidepressants in primary STP, specific partitioning coefficient $\left(\mathrm{K}_{\mathrm{d}}\right)$ values for antidepressants and metabolites to sewage sludge were estimated. The $K_{d}$ coefficients were calculated using the ratio [Sludge] / [Effluent]; where [Sludge] is the concentration of antidepressants in sewage sludge $(\mathrm{ng} / \mathrm{kg}$ ) and [Effluent] is the concentrations of antidepressants in final effluent (ng/L) [36]. The obtained $K_{d}$ values were applied to evaluate the affinity of compounds to primary STP sludge. The $K_{d}$ values were lowest for VEN, DVEN, and CAR (Table 2) with values ranging from 21 to $72 \mathrm{~L} / \mathrm{kg}$. With $\log$ $K_{d}$ values $\leq 2$, sorption to solid matter for VEN, DVEN, and CAR is therefore defined as negligible [36]. Higher sorption behaviour is expected for SER, DSER, FLU, and CIT which have higher relative $K_{d}$ values (Figure 3).

\section{Antidepressants in treated effluent - ozonation}

Ozonation of the primary-treated effluent did degrade antidepressants with higher efficiency, yielding a mean removal efficiency of $88 \%$ when $5 \mathrm{mg} / \mathrm{L}$ of ozone was applied (Table 3). Ten (10) of the 13 compounds initially present in the effluent had removal efficiencies $\geq 92 \%$ (Figure 4). Only three substances (CIT, AMI, and VEN) yielded lower removal efficiencies, being 34, 66, and 56\% respectively. As discussed in background section, the ozonation mechanism is directly affected by the ozone stability. Thus, scavengers compounds (e.g. carbonate, bicarbonate, dissolved organic and humic acids) present in effluent may have slowed down the ozone decomposition by inhibiting the free-radical reaction chain, and consequently the formation of hydroxyl radicals $\mathrm{OH}$ - necessary to degrade saturated aliphatic carbon chain on molecules [28]. Since, CIT, AMI and VEN have long tertiary amine aliphatic chains on their chemical structures, steric hindrance may have prevented ozone reactions normally expected at specific sites of the molecules [37]. In present study, it is very difficult to assess the relative importance of direct ozone-mediated transformations, and thereby to draw a general conclusion about each compound and

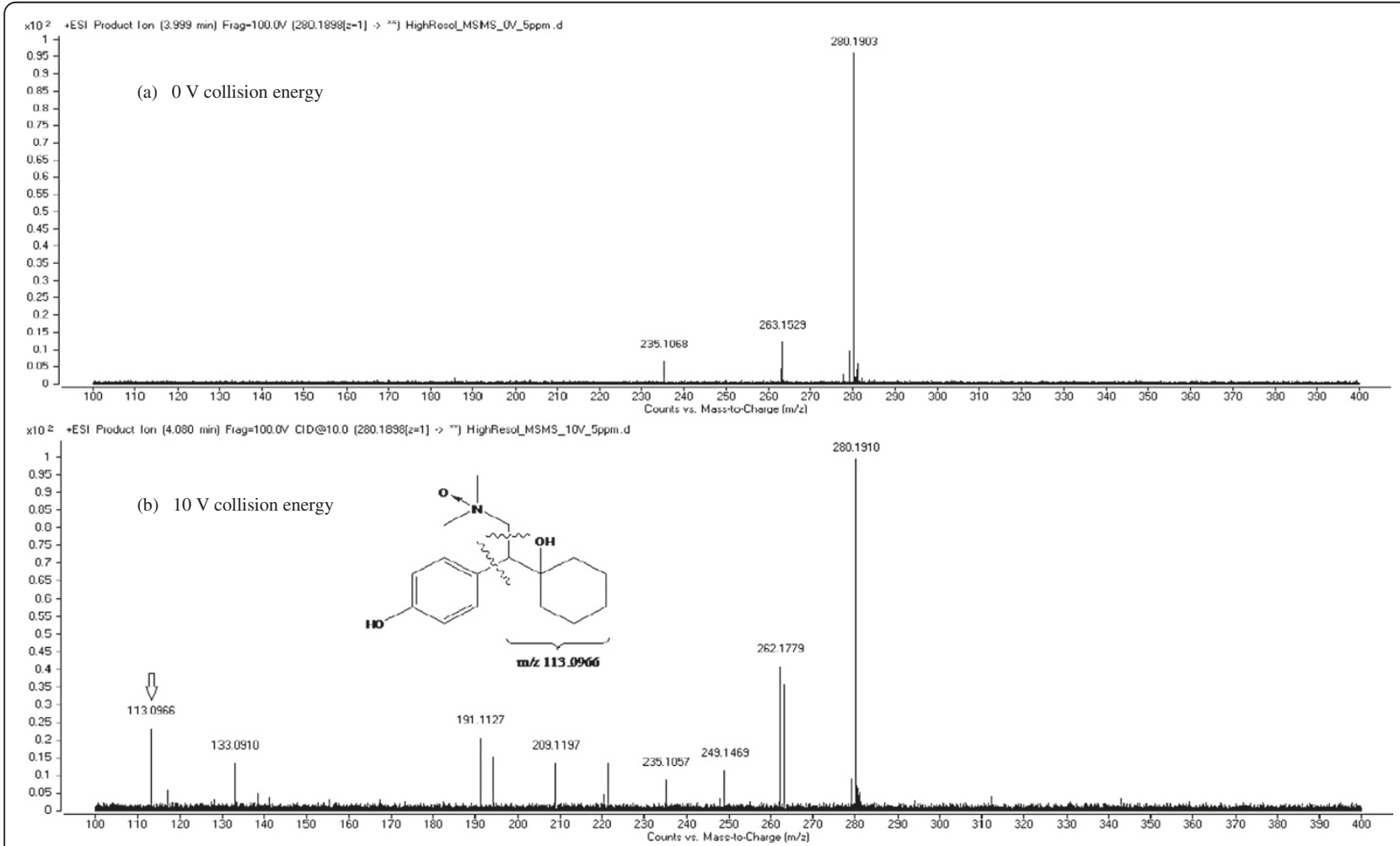

Figure 7 LC-QqToFMS mass spectra of $\mathrm{N}$-oxide DVEN in disinfected effluent $\left(\mathrm{O}_{3}\right.$ concentration: $\left.5 \mathrm{mg} / \mathrm{L}\right)$ : product ions at $0 \mathrm{~V}$ collision energy (a) and $10 \mathrm{~V}$ collision energy (b). 
transformation during ozonation in a single matrix with varying $\mathrm{OH} \bullet$ scavenging capacities, under a certain $\mathrm{pH}$ condition. Obviously, the work presented therein was not intended to the understanding of ozonation mechanisms. However, as reported by Zwiener and Frimmel [38], socalled radical scavengers compete with pharmaceuticals for the $\mathrm{OH}$-radicals and by this decrease the degradation kinetics of the targeted pharmaceuticals. Nevertheless, removal efficiency increased to $94 \%$ for most compounds using an optimal ozone dose of $9 \mathrm{mg} / \mathrm{L}$ (Figure 4). At the highest ozone treatment tested (i.e. $13 \mathrm{mg} / \mathrm{L}$ ), all antidepressants were oxidized and degraded from primary-treated effluent samples. Current limitation of the analytical method may have lead to undetected polar compounds that would require different chromatographic and instrumental adjustments. However, Snyder et al. [26] have reported very similar removal efficiencies for CAR (> 99\%) and FLU (> 93\%) for comparable effluent samples treated with $3.6 \mathrm{mg} / \mathrm{L}$ of $\mathrm{O}_{3}$. Under controlled conditions using a 5-L glass jacketed reactor, Rosal et al. [39] observed high removal efficiencies for CAR (98\%), CIT (93\%), FLU (100\%), and VEN (88\%) in wastewater samples exposed to $2.4-6.1 \mathrm{mg} / \mathrm{L}$ of $\mathrm{O}_{3}$ for less than 5 min.

\section{Characterization of new by-products by LC-QqToFMS}

In this study, the two most abundant antidepressants detected in raw sewage were VEN and its $N$-desmethyl metabolite DVEN. Therefore, primary-treated effluent samples previously treated with $\mathrm{O}_{3}$ at different concentrations were screened by LC-QqToFMS to confirm the presence of related by-products of these two compounds.

Initial tests performed on treated effluent extracts $\left(\mathrm{O}_{3}\right.$ dose: $\left.5 \mathrm{mg} / \mathrm{L}\right)$ in high resolution tandem MS mode using a mass range of $\mathrm{m} / \mathrm{z} 100-400$ (specific collision energy: $0 \mathrm{~V}$ ) enabled the positive detection of $\mathrm{N}$-oxide byproduct precursor ions for VEN $(\mathrm{m} / z$ 294.2059, accurate mass error: -3.40 ppm) and DVEN $(\mathrm{m} / z$ 280.1903, accurate mass error: $-3.21 \mathrm{ppm}$ ). The chromatograms and mass spectrums of both characterized by-products are depicted respectively in Figures 5, 6a, and 7a. Precursor $[\mathrm{M}+\mathrm{H}]^{+}$ions were isolated in the first quadrupole of the QqToF and then fragmented in the collision cell at $10 \mathrm{~V}$ in order to perform accurate mass measurements on the resulting fragment ions. Isolation and fragmentation of the precursor ion of $\mathrm{N}$-oxide VEN $(\mathrm{m} / \mathrm{z} 294.2057$, accurate mass error: $-4.08 \mathrm{ppm}$ ) generated a product ion at $\mathrm{m} / \mathrm{z}$ 127.1125 (Figure 6b). This ion fragment corresponds to $\left[\mathrm{C}_{8} \mathrm{H}_{14} \mathrm{O}+\mathrm{H}\right]^{+}$and has an accurate mass error from theoretical values of $1.57 \mathrm{ppm}$. As for the $N$-oxide DVEN when its precursor ion at $\mathrm{m} / z 280.1910$ (accurate mass error: $-0.71 \mathrm{ppm}$ ) was isolated and fragmented, an ion at $\mathrm{m} / z 113.0966$ was observed that could be interpreted as $\left[\mathrm{C}_{7} \mathrm{H}_{12} \mathrm{O}+\mathrm{H}\right]^{+}$with an accurate mass error of $\pm 0.00 \mathrm{ppm}$ (Figure 7b). During MS/MS characterization, it was decided to keep a large isolation width of the quadrupole (e.g. $4 \mathrm{~m} / \mathrm{z}$ ) to increase sensitivity. Hence, MS/MS mass spectra of $N$-oxide VEN and DVEN likely contained product ions of other molecules that may have interfered with the mass spectra interpretation. According to European Commission Decision 2002/657/EC [40], at least 4 "identification" points are required in order to confirm the presence of a substance. Since one high-resolution precursor ion and one high-resolution product ion were obtained during experiments (total identification points: $2+$ $2.5=4.5$ ), the results of our study (with accurate mass errors $< \pm 5.00 \mathrm{ppm}$ ) were considered sufficient to confirm the presence of the $\mathrm{N}$-oxide by-products.

Additional LC-QqToFMS analysis performed on effluent extracts previously treated with $9 \mathrm{mg} / \mathrm{L}$ of $\mathrm{O}_{3}$ confirmed also the presence of both $\mathrm{N}$-oxide by-products. When the concentration of $\mathrm{O}_{3}$ reached $13 \mathrm{mg} / \mathrm{L}$, none of the byproducts were detected in corresponding effluent samples. This suggests that an optimal $\mathrm{O}_{3}$ dosage would be required to completely degrade the $\mathrm{N}$-oxide by-products from treated effluents. Additional tests performed on raw sewage (influent) and primary-treated effluent confirmed the absence of the two $\mathrm{N}$-oxide by-products prior ozone treatments. To our knowledge, the present study is the first one to report the characterization of antidepressant by-products in municipal effluent samples after experimental ozone treatment.

\section{Conclusions}

This study described the fate and behavior of antidepressants and their $\mathrm{N}$-desmethyl metabolites in a primary STP following ozone treatment. Effluent ozonation led to higher mean removal efficiencies than current primary treatment, and therefore has represented a promising strategy for the elimination of antidepressants in urban wastewaters. However, the use of $\mathrm{O}_{3}$ has produced $\mathrm{N}$-oxide by-products with unknown toxicity. Of particular concern is the potential that removal of pharmaceuticals following wastewater disinfection using advanced oxidation process (i.e. ozonation) could generate by-products of similar parent chemical structures that would need to be identified, quantified and evaluated for their toxicity.

\section{Additional file}

Additional file 1: Optimized LC-(ESI+) QqQ conditions for the

analysis of antidepressants. The supporting document reports the instrumental LC-MS/MS parameters.

Competing interests

The authors declare that they have no competing interests.

\section{Authors' contributions}

AL performed the main part of the experiments and drafted the manuscript. MB performed ozone treatment experiments and helped analyzing the data. CG and SS helped interpreting the results and coordinated the manuscript 
writing. BB helped analyzing the data and drafting the manuscript. All the authors read and approved the final manuscript.

\section{Acknowledgements}

The authors gratefully acknowledge the city of Repentigny for providing sewage and biosolid samples. This work was funded by the Chemica Management Plan - Health Canada and the St. Lawrence Action Plan.

\section{Author details}

Environment Canada, Wastewater and Effluents Section, Water Science and Technology Directorate, 105 McGill Street, Montreal, Quebec H2Y 2E7, Canada. ${ }^{2}$ École Polytechnique de Montréal, Department of Civil, Geological and Mining Engineering, P.O. Box 6079, Succursale Centre-ville, Montreal, Quebec H3C 3A7, Canada. ${ }^{3}$ Department of Chemistry, Université de Montréal, P.O. Box 6128, Succursale Centre-ville, Montreal, Quebec H3C 3J7, Canada.

Received: 20 September 2012 Accepted: 22 January 2013

Published: 25 January 2013

\section{References}

1. Halling-Sørensen B, Nors Nielsen S, Lanzky PF, Ingerslev F, Holten Lützhøft $H C$, Jørgensen SE: Occurence, fate and effect of pharmaceutical substances in the environment - A review. Chemosphere 1998, 36:357-393.

2. Daughton EG, Ternes TA: Pharmaceuticals and personal care products in the environment: agents of subtle change? Environ Health Perspect 1999, 107:907-938.

3. Heberer T: Occurence, fate and removal of pharmaceuticals residues in the aquatic environment: A review of recent research data. Toxicol Lett 2002, 131(1-2):5-17.

4. Ternes TA: Occurrence of drugs in German sewage plants and rivers. Water Res 1998, 32:3245-3260.

5. Oulton RL, Kohn T, Cwiertny DM: Pharmaceuticals and personal care products in effluent matrices: a survey of transformation and removal during wastewater treatment and implications for wastewater management. J Environ Monit 2010, 12:1956-1978.

6. Vasskog T, Anderssen T, Pedersen-Bjergaard S, Kallenborn R, Jensen E: Occurrence of selective serotonin reuptake inhibitors in sewage and receiving waters at Spitsbergen and in Norway. J Chromatogr A 2008, 1185:194-205.

7. Van Rooyen GF, Badenhorst D, Swart KJ, Hundt HKL, Scanes T, Hundt AF Determination of carbamazepine and carbamazepine 10,11-epoxide in human plasma by tandem liquid chromatography-mass spectrometry with electrospray ionisation. J Chromatogr B 2002, 769:1-7.

8. Calisto V, Esteves VI: Psychiatric pharmaceuticals in the environment Chemosphere 2009, 77:1257-1274.

9. Fong PP: Antidepressants in aquatic organisms: a wide range of effects. In Pharmaceuticals and Personal Care Products in the environment. Edited by Daughton CG, Jones-Lepp TL. Washington, USA: Scientific and regulatory issue, ACS Symposium series; 2001:264-281.

10. Gagné F, Blaise C, Fournier M, Hansen PD: Effects of selected pharmaceutical products on phagocytic activity in Elliptio complanata mussels. Comp Biochem Physiol 2006, C143:179-186.

11. Mennigen JA, Lado WE, Zamora JM, Duarte-Guterman P, Langlois VS, Metcalfe CD, Chang JP, Moon TW, Trudeau VL: Waterborne fluoxetine disrupts the reproductive axis in sexually mature male goldfish, Carassius auratus. Aquat Toxicol 2010, 100:354-364.

12. Lajeunesse A, Gagnon C, Gagné F, Louis S, Čejka P, Sauvé S: Distribution of antidepressants and their metabolites in brook trout exposed to municipal wastewaters before and after ozone treatment - Evidence of biological effects. Chemosphere 2011, 83:564-571.

13. Lazzara R, Blázquez M, Porte C, Barata C: Low environmental levels of fluoxetine induce spawning and changes in endogenous estradiol levels in the zebra mussel Dreissena polymorpha. Aquat Toxicol 2012 106-107:123-130.

14. Rúa-Gómez P, Püttmann W: Impact of wastewater treatment plant discharge of lidocaine, tramadol, venlafaxine and their metabolites on the quality of surface waters and groundwater. J Environ Monit 2012, 14:1391-1399.
15. Lajeunesse A, Gagnon C, Sauvé S: Determination of basic antidepressants and their $\mathrm{N}$-desmethyl metabolites in raw sewage and wastewater using solid-phase extraction and liquid chromatography-tandem mass spectrometry. Anal Chem 2008, 80:5325-5333.

16. Schultz MM, Furlong ET: Trace analysis of antidepressants pharmaceuticals and their select degradates in aquatic matrixes by LC/ESI/MS/MS. Anal Chem 2008, 80:1756-1762

17. Metcalfe CD, Chu S, Judt C, Li H, Oakes KD, Servos MR, Andrews DM: Antidepressants and their metabolites in municipal wastewater, and downstream exposure in an urban watershed. Environ Toxicol Chem 2010, 29:79-89.

18. Radjenović J, Jelić A, Petrović M, Barceló D: Determination of pharmaceuticals in sewage sludge by pressurized liquid extraction (PLE) coupled to liquid chromatography-tandem mass spectrometry. Anal Bioanal Chem 2009, 393:1685-1695.

19. Hörsing M, Ledin A, Grabic R, Fick J, Tysklind M, la Cour Jansen J, Andersen HR: Determination of sorption of seventy-five pharmaceuticals in sewage sludge. Water Res 2011, 45:4470-4482

20. Lajeunesse A, Smyth SA, Barclay K, Sauvé S, Gagnon C: Distribution of antidepressant residues in wastewater and biosolids following different treatment processes by municipal wastewater treatment plants in Canada. Water Res 2012, 46:5600-5612.

21. Oller I, Malato S, Sánchez-Pérez JA: Combination of advanced oxidation Processes and biological treatments for wastewater decontamination A review. Sci Tot Environ 2011, 409:4141-4166.

22. Benotti M, Stanford B, Wert E, Snyder S: Evaluation of a photocatalytic reactor membrane pilot system for the removal of pharmaceuticals and endocrine disrupting compounds from water. Water Res 2009, 43:1513-1522.

23. Wert E, Rosario-Ortiz F, Snyder S: Effect of ozone exposure on the oxidation of trace organic contaminants in wastewater. Water Res 2009, 43:1005-1014

24. Méndez-Arriaga F, Otsu T, Oyama T, Gimenez J, Esplugas S, Hidaka H, Serpone N: Photooxidation of the antidepressant drug fluoxetine $\left(\right.$ Prozac $\left.^{\circledR}\right)$ in aqueous media by hybrid catalytic/ozonation processes. Water Res 2011, 45:2782-2794.

25. Huber MM, Göbel A, Joss A, Hermann N, Löffler D, Mcardell CS, Ried A, Siegrist $H$, Terne TA, von Gunten U: Oxidation of pharmaceuticals during ozonation of municipal wastewater effluent: A pilot study. Environ Sci Technol 2005, 39:4290-4299.

26. Snyder SA, Wert EC, Rexing DJ, Zegers RE, Drury DD: Ozone oxidation of endocrine disruptors and pharmaceuticals in surface water and wastewater. Ozone Sci Eng 2006, 28:455-460.

27. Gagnon C, Lajeunesse A, Cejka P, Gagné F, Hausler R: Degradation of selected acidic and neutral pharmaceutical products in a primary-treated wastewater by disinfection processes. Ozone Sci Eng 2008, 30:387-392.

28. Langlais B, Reckhow DA, Brink DR: Chapter II: Fundamental aspects. In Ozone in water treatment - Application and engineering. AWWA Research Association / Compagnie Générale des eaux. Edited by Langlais B, Reckhow DA, Brink DR. Michigan, USA: Lewis publishers inc; 1991:11-79.

29. Tomiyasu $H$, Fukutomi $H$, Gordon G: Kinetics and mechanism of ozone decomposition in basic aqueous solution. Inorg Chem 1985, 24:2962-2966.

30. Dodd MC, Rentsch D, Singer HP, Kohler H-PE, von Gunten U: Transformation of $\beta$-Lactam antibacterial agents during aqueous ozonation: reaction pathways and quantitative bioassay of biologicallyactive oxidation products. Environ Sci Technol 2010, 44:5940-5948.

31. Elmghari-Tabib M, Laplanche A, Venien F, Martin G: Ozonation of amines in aqueous solutions. Water Res 1982, 16:223-229.

32. Elmghari-Tabib M, Dalouche A, Faujour C, Venien E, Martin G, Legeron JP: Ozonation reaction patterns of alcohols and aliphatic amines. Ozone $\mathrm{SCl}$ Eng 1982, 4:195-205.

33. Standard method 2350. Oxidant demand / Requirement:: Approved by SM Committee; 2007.

34. U.S. Environmental Protection Agency (EPA): Standard method 4500-03 B for ozone, Standard methods for the examination of water and wastewater. 21st edition. U.S: Environmental Protection Agency (EPA); 2005.

35. Lajeunesse A, Gagnon C: Determination of acidic pharmaceutical products and carbamazepine in roughly primary-treated wastewater by solid-phase extraction and gas chromatography-tandem mass spectrometry. Intern J Environ Anal Chem 2007, 87:565-578. 
36. Deegan AM, Shaik B, Nolan K, Urell K, Oelgemöller M, Tobin J, Morrisey A: Treatment options for wastewater effluents from pharmaceutical companies. Int J Environ Sci Tech 2011, 8:649-666.

37. Trimm DL: Chapter 4: The liquid phase oxidation of sulphur, nitrogen, and chlorine compounds. In Comprehensive chemical kinetics - Vol. 16 Liquid phase oxidation. Edited by Bamford CH, Tipper CFH. Amsterdam, The Netherlands: Elsevier Scientific Publishing Company; 1980:205-249.

38. Zwiener $\mathrm{C}$, Frimmel $\mathrm{FH}$ : Oxidative treatment of pharmaceuticals in water. Water Res 2000, 34(6):1881-1885.

39. Rosal R, Rodríguez A, Perdigón-Melón JA, Petre A, García-Calvo E, Gómez MJ, Agüera A, Fernández-Alba AR: Occurrence of emerging pollutants in urban wastewater and their removal through biological treatment followed by ozonation. Water Res 2010, 44:578-588.

40. Commission of the European Communities: Commission Decision (2002/657/EC) of 12 August 2002: Implementing Council Directive 96/23/EC concerning the performance of analytical methods and the interpretation of results. Off J Eur Commun 2002, (8):L221-17. Internet access: http:/www.ecolex.org.

doi:10.1186/1752-153X-7-15

Cite this article as: Lajeunesse et al:: Ozone oxidation of antidepressants in wastewater -Treatment evaluation and characterization of new byproducts by LC-QToFMS. Chemistry Central Journal 2013 7:15.

\section{Publish with ChemistryCentral and every scientist can read your work free of charge \\ "Open access provides opportunities to our colleagues in other parts of the globe, by allowing anyone to view the content free of charge." \\ W. Jeffery Hurst, The Hershey Company. \\ - available free of charge to the entire scientific community \\ - peer reviewed and published immediately upon acceptance \\ - cited in PubMed and archived on PubMed Central \\ - yours - you keep the copyright \\ Submit your manuscript here: \\ http://www.chemistrycentral.com/manuscript/<smiles>c1ccccc1</smiles> Chemistry Central}

